\title{
Examining the relationship between personality, organizational political skill and perceived team performance in a multinational military staff exercise context
}

DOI 10.1515/jms-2016-0003

Received January 25, 2016; accepted August 17, 2016

\begin{abstract}
Military staffs are composed of many smaller teams that are interdependent upon each other for a positive functioning level of the whole staff. Many factors can improve or harm the harmony of the staff. Recently, there has been an increased interest in the soft factors that may affect team performance. The purpose of this study was to examine the relationship between the Big Five personality dimensions, political skill and perceived team performance in a multinational staff training event. The sample included 185 military staff officers (49\% response rate). The results indicated that the personality dimension Emotional stability and Political skill had a limited, yet statistically significant, predictive power on team performance. Practical considerations and future research directions are suggested.
\end{abstract}

Keywords: personality, team performance, political skills, military

\section{Introduction}

Military staff work is composed of the contributions of several smaller teams that are interdependent upon each other for the functioning level of the whole staff. Hittle and DeWitt (2012) note that higher-level staffs are comprised of

\footnotetext{
*Corresponding author: Alicia Ohlsson, Department of Security, Strategy and Leadership, Swedish Defence University, Karlstad, Sweden

Erik Hedlund, Department of Security, Strategy and Leadership, Swedish Defence University, Stockholm, Sweden

Gerry Larsson, Department of Security, Strategy and Leadership, Swedish Defence University, Karlstad, Sweden and Department of Public Health, Hedmark University College, Elverum, Norway
}

smaller teams, which include staff members that encompass specialty skill sets, in order to reach greater results than one individual could do on their own. Therefore, considerable focus is placed upon the functioning levels of teams.

Team performance is one of several factors that is often evaluated and worked upon in order to increase overall staff effectivity. This is accomplished on site in varying contexts and in training environments. Hard skills such as routines, procedures and hierarchy have traditionally been the focal point in military training and development; however, with increasing empirical research focusing on soft skills in leadership (interpersonal skills) and team performance, the military has also increased its concern with such factors (Blass and Ferris 2007; Laker and Powell 2011).

Factors such as personality and varying constructs of the broad category of social effectiveness, which includes concepts such as emotional intelligence, practical intelligence, self-monitoring, social skills, etc., have recently emerged as important psychological factors that can affect team performance (Bell 2007; Fisher et al. 2012; Feyerherm and Rice 2002; Lvina et al. 2015). For a review of social effectiveness constructs, refer to Ferris et al. (2002).

Ferris et al. (2005) developed the Political Skill Inventory (PSI) to measure an individual's social effectiveness in the work place, and it includes four distinct social interaction dimensions: networking ability, apparent sincerity, social astuteness and interpersonal influence. This concept is built upon Mintzberg's $(1983,1985)$ earlier concept of 'political skill', referring to an individual's ability to persuade, influence and control others in order to be effective. Ferris et al. (2005) added that political skill is a contextual understanding of others at work and their ability to influence others' actions, which advances their own or an organization's agenda. A growing body of research asserts that top performers are differentiated by their well-developed political skill ability (Blass and Ferris 2007; Blickle et al. 2009; Ferris et al. 2005; Mintzberg 1985; Spencer and Spencer 1993). 
A new interest has arisen in the concept of social effectiveness in team dynamics (Ahearn et al. 2004; Lvina et al. 2015) due to the dyadic relationship of influence and compromise (Jensen 2007). However, Lvina et al. (2015) argue that politically skilled individuals are talented at achieving beneficial individualistic outcomes, but that it may be detrimental to collective goals. As previously highlighted, there is a fine balance of the dyadic relationships of influence and compromise in group dynamics (Jensen 2007).Therefore, examination of an individual's political skills and team performance is an interesting topic for investigation in varying contexts.

As previously mentioned, another soft factor that has been suggested to be connected to influence is personality. Hogan and Shelton (1998) state that social skills and/or personality alone cannot direct influence. They postulate that the interaction between personality and social skills is what determines an individual's ability to successfully influence others. A few studies have shown statistical associations between the PSI and the Big Five dimensions of personality. Ferris et al. (1999) found that Political skills were correlated to Extraversion $(r=0.28$, $P<0.01)$ and Conscientiousness $(r=0.25, P<0.01)$. These findings, however, were not connected to performance. Ahearn et al. (2004) found that a leader's Political skill scores accounted for a significant increase in team performance variance beyond the factor of team Empowerment ( $\left.\beta=0.734, \Delta R^{2}=0.035, P<0.01\right)$. This demonstrates the possibility that leaders may be able to improve team performance through the use of political skills. However, this study did not examine personality as a factor of interest and, according to their own proclaimed study limitations; they used an earlier version of the PSI (Ferris et al. 1999), which included only six items to measure political skill. The most current scale has been developed further and includes 18 items to capture a broader spectrum of social effectivity in the workplace (Ferris et al. 2005).

Finally, Blickle et al. (2008) examined both personality and political skill in relation to an individual's job performance. Their investigation using hierarchical regression analysis showed that the interaction between Political skill and Agreeableness was significant, explaining incremental variance in job performance $(\beta=0.125, P<0.05$, $\left.\Delta R^{2}=0.015\right)$. This indicates that individuals who scored high on both Agreeableness and Political skill demonstrated greater job performance than those who scored low on each factor respectively or combined. Their study investigated the personality, political skill and job performance of individuals in varying working contexts, therefore making the interpretation of the importance of context difficult to analyze based on a particular occupation.
It also does not shed any light on how these constructs may relate or predict performance in a team setting.

In sum, the focus on soft skills in team performance has increased. Political skills have shown connections with increased team performance. Different dimensions, such as Extraversion, Agreeableness, Conscientiousness, Openness and Emotional stability, of the Big Five Personality construct have demonstrated positive significant relationships with Political skills, and the combined interaction of the aforementioned factors has demonstrated a positive interaction effect on an individual's job performance. However, to our knowledge, the combined elements of an individual's personality (trait) and organizational political skill (skill) in connection to perceived team performance have yet to be tested in a military setting.

\subsection{Research aims}

Drawing on the limited previous research found in organizational contexts, our research aimed to examine the relationships between an individual's personality variables and political skill, as well as determine how these two sets of conditions are associated with perceived team performance in a military context. Based on previous research, the following predictions were tested:

- Hypothesis 1: There will be positive, statistically significant correlations between the Big Five personality model dimensions Extraversion, Conscientiousness and Agreeableness on the one hand and organizational Political skill on the other.

- Hypothesis 2: There will be positive, statistically significant associations between these above mentioned personality dimensions and the Political Skill Inventory on the one hand and self-ratings of team performance on the other.

\section{Method}

\subsection{Participants}

A multinational staff exercise was run by the Swedish Armed Forces and the Swedish Defence University. There were 375 active military personnel participants in the training exercise and 185 in that group chose to answer the study questionnaire. Therefore, the sample represented $49 \%$ of the target audience. The sample consisted of 104 (56.2\%) officers from the Swedish National University, 43 (23.2\%) from the Finnish Defence University, 23 (12.4\%) 
from the Baltic Defence College, one (0.5\%) from the Austrian National Defence Academy, 11 (5.9\%) from the Swiss Armed Forces and two (1.1\%) officers labeled as 'other', non-specified, generating a total of 185 officer candidates. The sample was composed of 176 males (95.1\%) and nine females (4.9\%). Regarding the position, 57 (30.8\%) were section leaders or deputy leaders and 128 (69.2\%) were regular staff members.

\subsection{Procedure}

All 375 military personnel were asked to participate in the study. The study was conducted in the spring of 2015 and the Web-based questionnaires were filled in electronically by the participants at their own convenience. All answers were anonymous. The questionnaires were administered immediately following the military training exercise, after the military personnel returned back to their participating educational facility, and the results were received electronically by the authors.

\subsection{Training environment}

The Swedish Armed Forces and the Swedish Defence University organize an annual international Combined Joint Staff Exercise for the purpose of training military officers to carry out effective staff work. The exercise is conducted in a simulated learning environment for individuals and teams (student officers) at the tactical and operational levels. The training environment includes Headquarter (HQ) centers at four different locations spread throughout Sweden. There are several different roles that the exercise participants engage in, and there is an observer who watches over the exercise and offers feedback and support to the different staff sections. The military staff is divided into teams with smaller sections composed of 5-15 staff members. They work in these small team settings to carry out staff work. One of the many aims of the exercise is to assess what factors contribute to and counteract team performance, respectively. Therefore, our research interests fall in line with a part of the exercise's aims.

\subsection{Ethics}

All informants were treated in accordance with human research principles formulated by the Swedish Research Council (2000).

\subsection{Measures}

Considering that the sample group was multinational, the scales were given in their native forms, namely, English.

\subsubsection{Personal variables}

These included the following demographic factors: gender, age and military position.

\subsubsection{Personality}

The Single Item Measures of Personality (SIMP: Woods and Hampson 2005) scale is a personality scale that measures the Big Five personality dimensions: (1) Extraversion, (2) Agreeableness, (3) Conscientiousness, (4) Openness and (5) Emotional Stability in a short and concise manner. This scale consists of five bipolar items (scale ranging from one to nine), presenting two dichotomous statements for each of the dimensions. Although it is a brief measurement scale, the SIMP has been shown to have both convergent and divergent validity (Woods and Hampson 2005).

\subsubsection{Organizational political skill}

This was measured through the PSI (Ferris et al. 2005), which is composed of 18 items. Participants responded on a seven-point Likert scale, with score one representing the lowest (strongly disagree) and seven the highest (strongly agree). As mentioned in the Introduction section, these items are categorized into four dimensions: (1) networking ability, (2) apparent sincerity, (3) social astuteness and (4) interpersonal influence. The scale also offers a total score reflecting an individual's Political skill ability and is often operationalized as a total score in the literature (e.g. Blickle et al. 2008; Huang et al. 2013; Shi et al. 2013). Our analysis used the total scale score, which had a Cronbach's alpha value of 0.91 .

\subsubsection{Team performance}

Participants responded on a seven-point Likert scale, with score one representing the lowest (strongly disagree) and seven the highest (strongly agree). This was measured through the following five questions: (1) Recently, this team seems to be "slipping" a bit in its level of performance and accomplishment, (2) Those who receive or 
use the work this team does often have complaints about their work, (3) The quality of work provided by this team is improving over time, (4) Critical quality errors occur frequently in this team and (5) Members of the staff within the Headquarters or in the Subordinate Headquarters who interact with this team often complain about how it functions. Scale scores were reversed on items 1, 2, 4 and 5, and the total performance scale reliability, estimated through Cronbach's alpha, was 0.77 .

\subsection{Data analyses}

Reliability, descriptive and correlation analyses were performed. In addition, a multiple linear regression analysis was conducted to assess the associations between Personality dimensions and Political skill variables on Perceived team performance. Statistical significance was assumed at $P<0.05$. All statistical analyses were performed using SPSS version 21 (IBM Corporation 2012, Route Somers, NY, USA).

\section{Results}

\subsection{Descriptive statistics and intercorrelations}

Table 1 reports the means, standard deviations and intercorrelations of the study variables. Beginning with the means, the table shows that the personality scales are fairly well centered around the scale's midpoint (score five). The means of the Political skill scales and the team performance scale are somewhat positively skewed. Statistically significant correlations are found between the personality scales Extraversion, Openness and Emotional Stability and the PSI total score, while the correlations for Agreeableness and Conscientiousness versus the PSI were non-significant. This means that Hypothesis No. 1 was partly confirmed. Turning to Hypothesis No. 2, Table 1 further shows that three personality scales (Extraversion, Openness and Emotional stability) and the PSI total score correlate significantly with Team performance. Thus, Hypothesis No. 2 was partly supported. It can also be noted that the personality scales, as should be theoretically expected, were almost unrelated to each other (only one out of ten possible correlations was statistically significant).

\subsection{Regression analysis}

A multiple linear regression analysis was conducted to assess the prediction potential between the variables that were found to be significantly positively correlated with Perceived team performance. First, Perceived team performance was designated as the dependent variable for the analysis, and Extraversion, Openness, Emotional stability and PSI were designated as the predictor variables. The results are shown in Table 2.

Looking at the predictive power of Extraversion, Openness, Emotional stability and PSI with the outcome variable Perceived team performance, the model as a whole explained $13.1 \%$ of the variance: $F(4,180)=7.94, P<0.001)$. This indicates that the variables of interest accounted for a limited, yet statistically significant, proportion of the variance in the outcome variable Perceived team performance.

Two of the individual predictor variables, namely, PSI and Emotional stability, made unique statistically significant contributions to team performance. In summary, two of the predictor variables were significantly associated with team performance, however, not as suggested in Hypothesis No. 2.

Tab. 1: Intercorrelations, means and standard deviations of the Big Five dimensions of personality, Political skill total score and perceived team performance $(n=185)$

\begin{tabular}{|c|c|c|c|c|c|c|c|c|c|}
\hline Variables & 1 & 2 & 3 & 4 & 5 & 6 & 7 & $M$ & $S D$ \\
\hline 1. Extraversion ${ }^{1}$ & - & & & & & & & 5.57 & 1.97 \\
\hline 2. Agreeableness ${ }^{1}$ & $-0.22^{\star \star}$ & & & & & & & 5.90 & 1.62 \\
\hline 3.Conscientiousness ${ }^{1}$ & 0.10 & -0.10 & - & & & & & 5.70 & 1.71 \\
\hline 4. Openness ${ }^{1}$ & 0.01 & 0.11 & -0.13 & - & & & & 5.31 & 1.85 \\
\hline 5. Emotional stability ${ }^{1}$ & 0.14 & 0.06 & 0.04 & -0.10 & - & & & 6.19 & 1.87 \\
\hline 6. PSI total score ${ }^{2}$ & $0.35^{\star *}$ & 0.17 & 0.07 & 0.14 & $0.17^{\star}$ & - & & 5.06 & 0.71 \\
\hline 7. Team performance ${ }^{2}$ & $0.17^{\star}$ & -0.07 & 0.12 & $0.15^{*}$ & $0.23^{\star *}$ & $0.32^{\star \star}$ & - & 5.71 & 0.95 \\
\hline
\end{tabular}

${ }^{*} P<<0.01 ; * P<0.05$.

${ }^{1} S$ cale scores could range from one (lowest degree) to nine (highest degree).

${ }^{2} \mathrm{~S}$ cale scores could range from one (strongly disagree) to seven (strongly agree). 
Tab. 2: Regression results for the association of the Big Five personality dimensions Extraversion, Openness and Emotional stability, and Political skills total score with perceived team performance $(n=184)$

\begin{tabular}{llc}
\hline $\begin{array}{l}\text { Dependent variable } \\
\text { (Perceived team performance) }\end{array}$ & \multicolumn{2}{c}{ Model } \\
\hline Predictor variables & Beta & $\boldsymbol{p}$ \\
\hline Extraversion & 0.06 & 0.459 \\
Openness & 0.13 & 0.067 \\
Emotional stability & 0.19 & 0.007 \\
PSI total score & 0.25 & 0.001 \\
$R^{2} /$ adjusted $R^{2}$ & \multicolumn{2}{c}{$0.150 / 0.131$} \\
\hline
\end{tabular}

\section{Discussion}

This study aimed to examine the relationships between an individual's personality dimensions and political skills and how these two sets of conditions are associated with perceived team performance in a military context. Hypotheses were generated based upon previous research and tested.

Looking at the relationship between personality dimensions and the PSI, Hypothesis 1 could be said to be partially supported because the investigation indicated that the PSI was correlated with Extraversion, which has previously been demonstrated by Ferris et al. (2005). However, the results from this study did not support the idea that Conscientiousness and Agreeableness, captured in the SIMP, were positively correlated to the PSI, which has previously been demonstrated in other research contexts (Ferris et al. 1999; Blickle et al. 2008). However, this study's results demonstrated that the personality dimension Emotional stability was also correlated to the PSI. This may be explained by the military profession, which requires soldiers to be 'emotionally fit', exemplified through high-functioning emotion resilience systems in extreme working contexts that military personnel may encounter (Algoe and Fredrickson 2011). In military staff work, it can mean contributing to decision processes that may directly affect the life and limb of others out in the field. Emotional stability has also been demonstrated to be one of the most common factors found in job performance evaluation and training contexts (Alessandri and Vecchione 2012; Judge and Bono 2001).

Now turning to the investigation of the associations between the Big Five personality factors and Political skills with self-ratings of team performance, the multiple regression analysis indicated that the personality dimension Emotional stability as well as Political skill had limited, yet statistically significant, predictive power on team performance. The emergence of the dimension Emotion stability as a predictor of team performance is a new contribution to previous research findings; therefore, Hypothesis 2 is not supported in the way it was originally conjured. The study gives a mild confirmation of Hogan and Shelton's (1998) assertions that better understanding of influence may be captured by a combination of soft factors, rather than by each factor on its own.

The positive effect of Emotional stability and Political skill on perceived team performance indicates that emotionally stable individuals have an advantage when it comes to the use of political skills, such as social astuteness, interpersonal influence, networking ability and apparent sincerity, and that this combined effect enhances team performance. However, the comparatively low adjusted $R^{2}$ value (0.13) indicates that Perceived team performance has multiple determinants in addition to those explained in this study.

This study contributes to the literature by offering an examination of the relationships between individuals' personality (captured in the Big Five dimensions of personality) and Political skill and how these two sets of conditions are associated with collective goals such as perceived team performance. As Jensen (2007) points out, there is a dialectic relationship between the individual and the team in group decision-making. On the one hand, it is rather individualistic because individuals behave according to personal motives and, on the other hand, you have interpersonal aspects of group cohesion and collective decision-making. Lvina et al. (2015) have argued that politically skilled individuals may be detrimental to collective goals. Despite this paradoxical relationship, this study showed a positive relationship between individuals' political skill and their perceived team performance. This could be explained by individuals' locus of control, meaning that the more they believe they are able to influence others, the higher their perception of team performance may be. However, these factors should be studied in additional contexts and career fields to truly understand the person-environment relationship that is specific to each career field.

Despite the study's contributions, there are several limitations that should be recognized. The first is that the study's setting was a coordinated training event; therefore, these relationships may look different in the natural work environment wherein interpersonal relationships take longer time to evolve and the social landscape is not heavily monitored by a formal event.

Personality was measured by a single-item measure for each dimension; although the internal validation and consistency areassumed to be acceptable, a more elaborate 
personality measure may have indicated different results. Performance was measured with a self-made measure due to lack of other brief performance measures suitable for the context. Moreover, the questionnaire was a self-report measure. There is always a risk for single-source bias when using self-report measures due to possible lessened objectivity in reporting information regarding one's self as well as social desirability bias (Podsakoff et al. 2003). Lastly, the questionnaires were given in their native form, English, to a multinational staff; therefore, there may have been language barriers in interpreting and responding to the questions. Considering these study limitations, the results should be interpreted with caution for any generalizable findings.

Practical considerations from this study's findings include the need for the Swedish Armed Forces to consider additional soft skill assessments and use of training tools for the recruitment of leaders and military staff members. Training in soft skills, including organizational Political skills, may improve the armed forces' military staff performance. It could also be useful in developing collaborative and negotiation abilities in internal (between military departments) and external contexts of the organization (in multinational settings). Personality factors may be useful in identifying individuals who have a natural talent for possibly learning political skills through training.

\section{References}

Ahearn, K., Ferris, G. R., Hochwarter, W. A., Douglas, C., \& Ammeter, A. (2004). Leader political skills and team performance. Journal of Management, 30(3), pp. 309-327.

Alessandri, G., \& Vecchione, M. (2012). The higher-order factors of the Big Five as predictors of job performance. Personality and Individual Differences, 53(6), pp. 779-784.

Algoe, S. B., \& Fredrickson, B. L. (2011). Emotional fitness and the movement of affective science from lab to field. American Psychologist, 66(1), pp. 35-42.

Bell, S. T. (2007). Deep level composition variables as predictors of team performance: A meta-analysis. Journal of Applied Psychology, 92(3), pp. 595-615.

Blass, F., \& Ferris, G. (2007). Leader reputation: The role of mentoring, political skill, contextual learning, and adaptation. Human Resource Management, 46(1), pp. 5-21.

Blickle, G., Meurs, J. A., Zettler, I., Solga, J., Noethen, D., Kramer, J., et al. (2008). Personality, political skill, and job performance. Journal of Vocational Behavior, 72(3), pp. 377-387.

Blickle, G., Kramer, J., Zettler, I., Momm, T., Summers, J., Munyon, T., et al. (2009). Job demands as a moderator of the political skill-job performance relationship. Career Development International, 14(4), pp. 333-350.
Ferris, G. R., Berkson, H. M., Kaplan, D. M., Gilmore, D. C., Buckley, M. R., Hochwarter, W. A., et al. (1999). Development and initial validation of the political skill inventory. In: Paper Presented at the 59th Annual National Meeting of the Academy of Management, Chicago.

Ferris, G. R., Perrewé, P. L., \& Douglas, C. (2002). Social effectiveness in organizations: Construct validity and research directions. Journal of Leadership and Organizational Studies, 9, pp. 49-63.

Ferris, G. R., Treadway, D. C., Kolodinsky, R. W., Hochwarter, W. W., Kacmar, C. J., Douglas, C., et al. (2005). Development and validation of the political skill inventory. Journal of Management, 31(1), pp. 126-152.

Feyerherm, A. E., \& Rice, C. L. (2002). Emotional Intelligence and team performance: The good, the bad and the ugly. The International Journal of Organizational Analysis, 10(4), pp. 343-362.

Fisher, D., Bell, S. T., Dierdorff, E. C., \& Belohlav, J. A. (2012). Facet personality and surface-level diversity as team mental model antecedents: Implications for implicit coordination. Journal of Applied Psychology, 97(4), pp. 825-841.

Hittle, J., \& DeWitt, L. (2012). The Military Staff: Its History and Development. Literary Licensing, LLC, Whitefish, MT.

Hogan, R., \& Shelton, D. (1998). A socioanalytic perspective on job performance. Human Performance, 11(2/3), pp. 129-144.

Huang, L., Frideger, M., \& Pearce, J. L. (2013). Political skills: Explaining the effects of nonnative accent on managerial hiring and entrepreneurial investment decisions. Journal of Applied Psychology, 98(6), pp. 1005-1017.

IBM Corp, Released 2012, IBM SPSS Statistics for Windows, Version 21.0. IBM Corp., Armonk, New York.

Jensen, J. (2007). Getting one's way in policy debates: Influence tactics used in group decision-making settings. Public Administrative Review, 67(2), pp. 216-227.

Judge, T. A., \& Bono, J. E. (2001). Relationship of core selfevaluations traits-self-esteem, generalized self-efficacy, locus of control, and emotional stability-with job satisfaction and job performance: A meta-analysis. Journal of Applied Psychology, 86(1), pp. 80-92.

Laker, D. R., \& Powell, J. L. (2011). The difference between hard and soft skills and their relative impact on training transfer. Human Resource Development Quarterly, 22(1), pp. 111-122.

Lvina, E., Johns, G., \& Vandenberghe, C. (2015). Team political skill composition as a determinant of team cohesion and performance. Journal of Management, published online, pp. 1-28.

Mintzberg, H. (1983). Power in and Around Organizations. Prentice Hall, Englewood Cliffs, NJ.

Mintzberg, H. (1985). The organization as a political arena. Journal of Management Studies, 22, pp. 133-154.

Podsakoff, P. M., MacKenzie, S. B., Lee, J. Y., \& Podsakoff, N. P. (2003). Common method biases in behavioral research: A critical review of the literature and recommended remedies. Journal of Applied Psychology, 40(5), pp. 879-903.

Shi, J., Johnson, R. E., Liu, Y., \& Wang, M. (2013). Linking subordinate political skills to supervise dependence and reward recommendations: A moderated mediation model. Journal of Applied Psychology, 98(2), pp. 374-384.

Spencer, L. M., \& Spencer, S. M. (1993). Competence at Work: Models for Superior Performance. John Wiley, NY, NY. 
Swedish Research Council. (2000). Riktlinjer för etisk värdering av medicinsk humanforskning: Forskningsetisk policy och organisation i Sverige, 2nd ed. [Guidelines for Ethical Assessment of Medical Research on Humans: Policy and Organization of Research Ethics in Sweden, 2nd ed.]. Swedish Research Council, Stockholm, Sweden.

Woods, S. A., \& Hampson, S. E. (2005). Measuring the big five with single items using a bipolar response scale. European Journal of Personality, 19(5), pp. 373-390.

\section{Biographical notes}

Mrs Alicia Ohlsson (MA Counseling/Clinical Psychology, University of North Texas, USA) is a researcher in psychology at the Department of Security, Strategy and Leadership at the Swedish Defence
University. She has published articles, book chapters and research reports in the areas of leadership and stress, emotion management and organizational psychology in military contexts.

Associate Professor Erik Hedlund (Ph.D., Stockholm University, Sweden) is the head of the leadership course on the advanced Command and Staff programme at the Swedish Defence University and is a member of the Armed Forces and Society's Editorial Board. He has researched and published in the areas of civil-military relations, military motivation and self-image, leadership and team learning.

Professor Gerry Larsson (Ph.D., Goteborg University, Sweden) is a licensed psychologist, professor of leadership psychology at the Swedish Defence University and adjunct professor of stress psychology at Hedmark University College, Norway. During the period 2004-2009, he also served as Vice President of the University. He has published extensively in the areas of leadership, stress, personality and organization. 